Article

\title{
Towards Evaluation the Cornerstone of Smart City Development: Case Study in Dalat City, Vietnam
}

\author{
Khoa Hoang Viet Bach ${ }^{1, *}$ and Sung-Kyun Kim ${ }^{2}$ \\ 1 Graduate School of Environmental Studies, Department of Landscape Architecture, Seoul National \\ University, Seoul 151-921, Korea \\ 2 College of Agriculture and Life Science, Department of Landscape Architecture \& Rural System engineering, \\ Seoul National University, Seoul 151-921, Korea; sung@snu.ac.kr \\ * Correspondence: khoahvb@snu.ac.kr
}

Received: 31 October 2019; Accepted: 16 December 2019; Published: 18 December 2019

check for updates

\begin{abstract}
Over the past decade, the process of urbanization in Vietnam has taken place rapidly, leading to strong social disturbances and causing cities to face many problems. All these challenges have put pressure on urban planning and governance to make adjustments to allow cities to become livable. Moreover, the quality of urbanization is reflected not only in growth but also in harmonious development in all aspects. The urban development process must accordingly be handled by more smart solutions. Smart city development is becoming a trend not only in urban areas all over the world but also in Vietnam. The paper aims to assess the initial phases of the smart city development process in Dalat City. It first evaluated a four-dimensional smart city's strategic elements of city vision and transformation known as Strengths-Weaknesses-Opportunities-Threats. Then, based on these analytical characteristics, an adaptive model for development is suggested. This paper extends the previous research on smart cities and draws attention to further study on smart city development in Vietnam.
\end{abstract}

Keywords: Smart city; SWOT Analysis; Municipal strategies; Dalat city

\section{Introduction}

Nowadays, more than half of the world's population lives in urban areas. According to the UN's forecast, by 2050, 54\% of the population in Asian countries will be concentrated in urban areas [1]. Cities around the world are facing enormous challenges and changes compared to 20 years ago by operating in economies, societies, and cultural ecosystems utterly different from the outdated urban models of the 20th century [2]. Persistent urban problems over the past 20 years include urban development, changing family models, the number of urban residents living in slums, informal settlements, and the challenge of providing public services [2,3]. The heavy burden on existing public infrastructure systems of cities has reached or far exceeded the design life, and infrastructure overload has also led to a range of environmental, transportation and health issues affecting the quality of life of people [4].

Besides, the process of globalization and integration also requires cities to improve their operational efficiency and competitiveness to attract investment resources to promote sustainable economic development [5]. From these issues, there have been a series of trends in the formation of smart cities, associated with the trend of the fourth industrial revolution [6]. Since 2011, the emergence and rapid development of the fourth industrial revolution has promoted the development of technology in the direction of connecting things, using cloud computing, big data analysis tools and artificial intelligence. The fourth industrial revolution was built on the foundation of the digital revolution, which erases the boundary between the physical world, the virtual world, and the biological world [6,7]. According to 
Information Handling Services Technology's forecast, from 2013 to 2025, the number of smart cities in the world will increase from 21 to at least 88 cities [8]. Many keys to new technologies are becoming an effective tool for deploying the construction of smart cities in areas such as energy, transportation, health care, information analysis and travel [7,9].

Faced with the need to solve the problems of urbanization and population growth, since the mid-2000s, several cities around the world have begun to actively apply information and communication technology solutions to address urban management and socio-economic development. Typically, solutions to solve the city issues such as transportation, health, or solutions to promote cities to develop their economy sustainably [9].

Currently, developed countries seek to renew their cities within stable infrastructure. Due to Vietnam's unique political system and central-local government relationship, smart city development in Vietnam exhibits different features and developmental paths from the Western development model of bottom-up, local autonomy, and inter-sectoral collaboration [10]. Vietnam still has many opportunities to build a new city by young and dynamic urban population, high internet coverage, a growing middle class, and the trend of extensive international integration [11]. The whole country has 63 provinces, including two centrally controlled cities, 15 cities in grade I, 21 cities in grade II, 42 cities and towns in grade III, and 68 towns and townships in grade IV and 626 townships in grade IV. Fifty percent of the urban population is concentrated in 16 big cities. Economic growth in urban areas reached 12-15\%; these urban centers contain socio-economic activities, innovation activities, education, scientific and technological research, production, trade, and international integration [12].

Despite being a nation with active economic development in Southeast Asia, however, the current situation of urban development in Vietnam shows many issues that need to be addressed. The highlights of urban development include congestion, pollution, and lack of housing in major cities [12,13]. Two cities, including Hanoi and Ho Chi Minh have problems in urban management, expanding chaos, suspended projects and a lack of connectivity infrastructure in newly expanded peripheral areas of most urban areas [12]. Meanwhile, medium and small cities lack the resources to develop. Less support for spillover urbanization leads to the imbalance of labor and settlement in the space of national development [13]. The gap between housing and the poor in urban areas is likely to be unstable when housing prices are beyond affordable for the majority of households and the real estate market is not transparent and protecting the weak [14]. The deteriorating quality of the urban environment, water, and air pollution threaten large cities [15].

The current development situation shows that it is necessary to prioritize adjustments in the current development management system from planning to implementation. In order to neutralize the pressure on population growth for urban areas, the Vietnam Prime Minister issued decision No. 950/QD-TTG 2018 approving the scheme on sustainable development of smart cities in Vietnam for the period of 2018-2025 and orientation to 2030 [16]. So far, Vietnam has nearly launched 20 projects on smart cities. The rapid development, and dissemination of information technology in Vietnam counted by the end of May 2017 including fixed broadband Internet subscribers reached 9.9 million and mobile broadband internet reached 49 million subscribers [17]. However, the limitations of rapid urbanization, low starting points, and limitations on economic potential as well as experience in urban development and management are a weakness of Vietnam in developing smart cities.

Simultaneously with the context of a dynamic fast-growing, socialist-oriented market economy in Vietnam, this paper aims to address the assessment of the possibility of building a smart city at Dalat city by developing a better understanding of the city's Strengths-Weaknesses-Opportunities-Threats. It can help local government, urban administrators, and smart city practitioners better grasp the foundation of the existing city and assist them in undertaking necessary actions to achieve the desired outcomes. The methodological approach adopted in this research focuses on SWOT analysis and suggests systematic strategic solutions and action plans. By developing such a framework, this study contributes to the efforts to help Dalat take the right steps for building a smart city. 


\section{Theoretical Framework}

\subsection{Smart City}

Today, city planning and management are the primary tasks of professionals because they will be the owners of complex and highly technical processes [18]. In the trend of globalization and sustainable development, it is no coincidence that smart cities are becoming more and more popular not only in developed countries but also in developing regions, countries, and localities. The smart city is the outcome of powerful technological tools, even an ecological and cultural system. It creates specific type of relations and a particular culture of the city [19]. Breakthroughs, as well as technological challenges, are seen as standards for social improvement [20]. The smart city idea has been a gradual and continuously evolving process spanning from early 20th century visions about the city of the future, which revolves around how technology can be used to infuse intelligence into the urban realm [21]. The forward-looking development approach to a smart city considers issues such as awareness, flexibility, transformability, synergy, individuality, self-decisiveness, and strategic behavior [22]. The main point of smart city development is improving people's lives, efficiency, and sustainability $[23,24]$. Beginning in the early 90 s with increasing interest in the relationship of urban development based on International Telecommunication Union perspectives will be central in the development and operation of the future city [25]. A city is considered smart when the operation process goes smoothly towards a harmonious and smart combination of six components: economy, people, governance, mobility, environment, and living [26].

In the smart city ecosystem, the areas of government development, city operations, service delivery, smart analytics will be positively addressed by ICTs and Internet of Things [22]. In theory, smart cities can produce efficient products, in the sense that citizens benefiting from that efficiency are more likely to be accepted [27]. Even though the management term bears the impression of a functional arrangement for governance, the options that it requires take the discussion to a deeper level of political and ethical choices [28]. Some studies identify that the policy context is essential for understanding smart city development, innovations in policy and management, as well as in technology, must have a reciprocal interaction with the political institution $[29,30]$. This ICT-based governance widely represents a collection of techniques, people, policies, practices, resources, social norms, and information that interact to support city governing activities $[8,22]$. Improving city governance and adjusting to the new realities of smart cities is essential. Issues such as market and political equilibrium in new scenarios or the adjustment of new security issues are major local political concerns, and represent an important challenge for smart city development [29]. Little literature on smart cities addresses issues related to governance. Smart governance describes as an essential characteristic of a smart city that is based on citizen participation, and private-public partnerships are accountable, responsive and transparent [31]. There is a wide array of previous research on smart city development that has highlighted governance issues as important success factors or significant challenges [32].

\subsection{Motivating Factors and Benefits}

Since its renovation in 1986, the urban population in Vietnam has started to grow rapidly and increasing economic transformation towards industrial production has created more jobs and economical products. The larger cities like Hanoi, Ho Chi Minh, and some medium-sized cities have achieved the fastest population growth rate in the past ten years [32]. The rapid pace of urbanization has caused a lot of pressures and adverse effects such as population explosion, overcrowding of public infrastructure and services, environmental pollution, traffic congestion and resource depletion. Besides, the current infrastructure does not meet the requirements of urban development, with a lack of shared databases, and data linkages between ministries and agencies [32,33]. The growing pressure of economic competition is not only from the rising population but also about attracting investment, developing jobs, attracting human resources. Moreover, peoples and businesses expect to be able to access information anytime, anywhere through computers and mobile devices, and live in a city 
with convenient transportation, good education and with a government-connected to the people [34]. In addition, current technology is developing at a dizzying pace while decreasing costs are driving cities to invest more and more in technology as a competitive advantage.

The essence of a smart city is the collection, connection, and utilization of data information to help citizens, businesses and governments to make decisions most accurately. A smart city, with a shared infrastructure that can be fully utilized across sectors, will allow full sharing of data information between citizens, businesses, and governments, and support the current needs of the municipality [35]. Cities marked on the world map as smart cities such as Barcelona, London etc. are the cities with high socio-economic development, and current infrastructure and modernization developing towards sustainability [36]. These cities have selected and tested the application of new generation technology in many different fields to operate the city more smartly and sustainably. The roadmap to build them into smart cities is divided into several stages, with the choice of which areas will be "smartized" being the first. Up to $40 \%$ of on-going projects are about smart government (e-government), followed by smart energy management systems (27\%) and distribution and control systems making intelligent water sources and intelligent traffic. Most of these projects are concentrated in European countries because they are supported by the government on anti-climate change goals [37]. In addition, Europe is also applying ICTs to many areas of life, so it is easier and more feasible to deploy and connect those fields. Smart cities have brought remarkable efficiency in the direction of sustainable urban development. The intelligent traffic management system in Stockholm has reduced traffic volume by 20\%, travel time by $50 \%$, and peak emissions by $10 \%$. The region with the second-largest number of projects today is the Asia Pacific, projects in Asia often tend to be supported by central governments, especially in China. China's 13th Five-Year Socio-Economic Development Plan also mentions the development of smart cities [38]. In North America, under the Obama administration, there has been much support for smart city construction projects, especially projects related to transportation [39]. Each city and country have their strategy depending on the development context. Thus, there are many ways to deploy toward the goal of becoming a smart city.

\section{Methodology}

This exploratory study is based on the SWOT analysis method approach. Performing analysis using the SWOT framework helps focus activities on areas where one is strong and has the most significant opportunity [40]. Also, SWOT will provide a big picture of the most important factors affecting survival and prosperity as well as action plans [41]. It is a widely used tool for analyzing internal and external environments to attain a systematic understanding of a strategic management situation. It encourages strategists to adopt a strategy that can best cope with the situation [41]. SWOT analysis is the preferred tool of analysts to begin operating the strategic planning process [42]. SWOT analysis can be used as a methodological tool to assess political context correctness, an important factor in determining the success of an individual or group [43]. SWOT analysis provides a clear summary statement of an organization's strategic position applied from organization to personals [44]. Unlike other tools that became quickly outdated with the fast development of management science, SWOT analysis is still prevalent [45]. Firstly, it fits alongside other theories and tools which emerged later. For example, a SWOT analysis may itself encompass several different forms of analysis [45]. Secondly, it provides strategy planners with a systematic but simple way of conducting SWOT analyses [46]. Besides, it can use by different types of organizations, including companies, non-profit organizations, government units, and even individuals [47]. While based on data and facts, the conclusions drawn from SWOT analysis are an expert opinion [48]. Data in this study are mainly from the internet, literature paper, official reports of government are collected and sorted into four categories: strengths, weaknesses, opportunities, and threats. Strengths and weaknesses generally stem from factors within the organization, whereas opportunities and threats usually arise from external factors. The identified factors put on the systematic strategic process diagram by mind mapping technique, it can develop to help in organizing categories and ideas. Mind maps have been used around the central problem 
to express ideas, created through content analysis, into a visual diagram [49]. It provides explicit imagery and insights by capturing all concepts related to a particular concern and paying attention to the relationships among concepts [50]. Conceptual maps stimulate the creation of ideas, rapid results, visual graphical representations, and the relation of generated ideas [49].

\section{Case Study}

The study area was set as Dalat city located in the central highland of Vietnam. With over 120 years of establishment and development, Dalat city has become a famous tourist city with outstanding characteristics and advantages. It known as the city of thousands of flowers, as recognized by the Vietnam government. Up to now, Dalat has become a famous domestic and international brand of tourism and agricultural high technology region of the country (Figure 1). In recent years, rapid urbanization has led to a series of problems arising in the process of economic, social security, and planning development, making Dalat city more complex than ever. The construction of a smart city is an opportunity for Dalat to widely apply modern science and technology to solve long-term problems and seize opportunities in socio-economic development, in line with the orientation of building Dalat with modern, convenient, and sustainable standards. Information technology application and other means to improve the quality of life, improve the performance of the local government, promote socio-economic development comprehensively and sustainability, improve capacity competitiveness with the goal of "building Dalat to become a smart city [between the] period of 2018-2025".

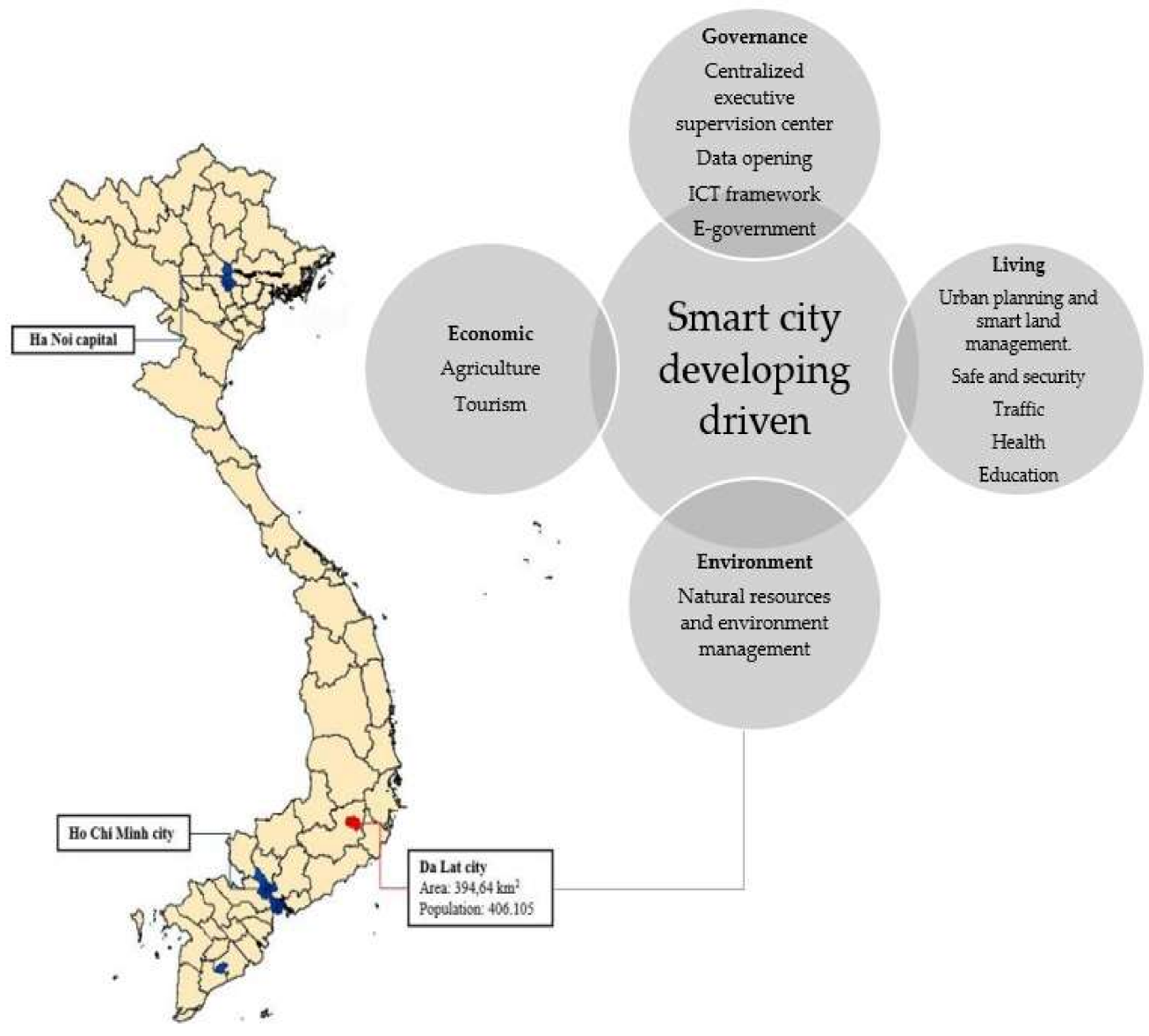

Figure 1. City location and drive for the development of smart city. 


\subsection{City Vision and Transformation-Strengths}

\subsubsection{Well Defined and Realistic Goals}

According to resolution No. 03-NQ/TW dated 13 July 2016 on developing Dalat city and its vicinity in the period of 2016-2020 with an orientation to 2030, Dalat city has an important political, socio-cultural and national defense position not only in the Lamdong province but also in the central highlands and Vietnam [51]. The city has the advantage of being highly conscious of investing and advocating for policy reform of government opening, the city government has defined specific development strategies (Figure 2). Smart city developing requires a clearly defined and realistic goal depending on the specific requirements and resources available [23]. In particular, the approach and roadmap need clear and adaptive scenarios depending on the context of each city. In addition, long-term goals, especially IoT factors, political institutions, civil rights as well as economic development conditions, must also pay attention [52].

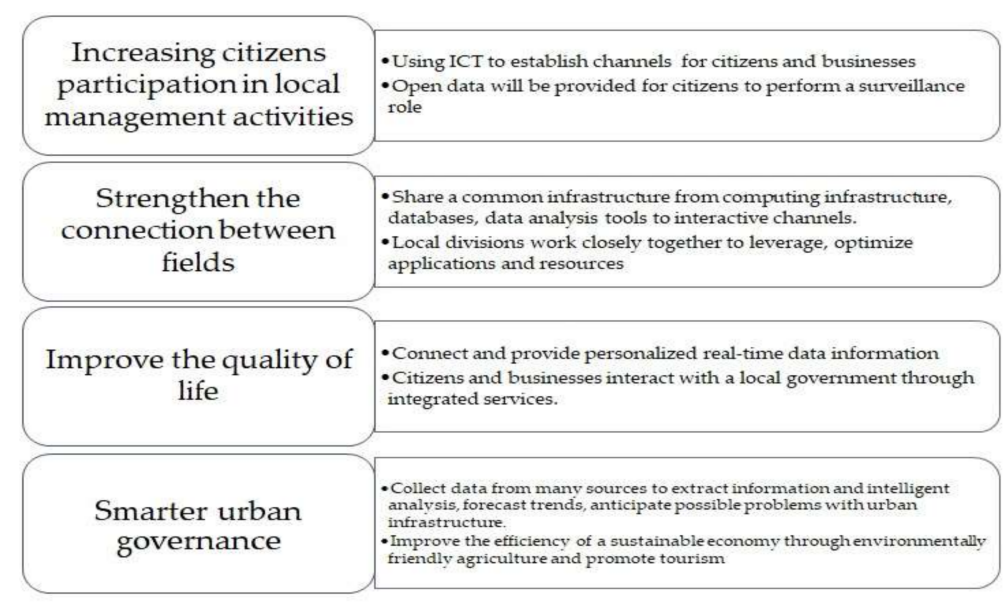

Figure 2. City government strategies in developing a smart city.

The development of a smart city is more complicated than traditional urban planning as it involves interactions between different stakeholders [21]. Smart city development should focus on the roadmap approach because almost the majority of smart city-related cases, the actual implementation is more about renovation rather than about building a completely new city [53]. By undertaking a roadmap approach focusing on transformation, the cities must focus on identifying and building their strengths [54]. The overall roadmap is divided into two phases based on the actual situation and orientation of socio-economic development and conditions of Dalat city (Figure 3).

2018-2020 Establish on sharing technology platform and priority areas (digital government, urban planning)

- Build up the technology infrastructure base on safe and secure platform.

-Focus on developing e-government by strengthening activities within the local government divisions, improving utilities. - Deploy several priority smart applications

- Open the control center to integrate tools and applications in various fields.

2021-2025 Implement synchronous solutions on a shared, expanded, and improved platform

-Deploying fields according to the roadmap: tourism, agriculture, health, education, transport, safety, and security

- Forming a data platform, providing open data

-Establishing the data analysis platform, forecasting, and supporting decision-making for city leaders

Figure 3. City developing roadmap. 


\subsubsection{Technological Innovation}

Smart ICT revolution and technology advancement have already set the required base for the smart city concept. ICT has transfigured human aspects of thinking, the way ubiquitous sensing and instrumentation, control and optimization, networking and service integration, and wireless connectivity have converged. It has made the citizens more situationally aware and smarter than ever [55]. Currently, the city's fixed-broadband subscriptions reach $95 \%$ of users, developing broadband applications and high-speed information transmission. Also, the city has invested nearly 6 billion dongs in upgrading IT equipment and the local area network, installing a one-stop electronic system [56]. Through the DalatOnline-iGov Connect software system developed by Vietnam Posts and Telecommunications, local people and business can carry out administrative procedures at the receiving and result returning unit via network environments such as submitting documents, quickly looking up the status of files, evaluating the service attitude of file-receiving staff, directly reflecting on the scene images of issues such as security and order, illegal construction, road encroachment, environmental sanitation and market prices. Also, the system has integrated applications that the city has deployed, such as an urban planning portal, electronic contact book, smart travel application, administrative map and information about new jobs [57].

\subsection{City Vision and Transformation-Weakness}

\subsubsection{Managerial and Organizational}

Building a vision for a smart city requires leadership with a high level of vision and determination, not only from the leaders of the government but also from the business manager, social organizations, and citizens [58]. Currently, city decisions still aim to solve each situation for the short term while the construction of a smart city process needs to spread from short, medium to long term $[59,60]$. Limited human resources in the ICT field are also embarrassing in forming a smart city operation division during construction. The city must choose outsourced ICT services to solve operational personnel problems [59]. In addition, the number of integrated services is still low, basically because the database of divisions is relatively independent. Especially the unconnected applications, many applications are synchronously invested by the city, but some vertical deployment applications have not been invested yet.

\subsubsection{Citizen's Awareness and Involvement}

Human capital is an integral part of smart city dynamics, the involvement of human resources should be a starting point instead of blindly considering that ICT and technology advancements will automatically transform and improve the city [61]. A smart city can build on the smart combination of applying the smart city concept of citizens and self-corrective activities of citizens who perceive the situation in a forward-looking way. Smart citizens of smart cities are not only categorized by education level but also the level of social interaction in addition to the concept of personal life connected with external world issues [62]. Current city problems can be solved with smart solutions from smart citizens through people's awareness, social engagement and learning, training and skill development [53]. The city has no detailed programs, wide communication broadcasting, and guides for citizens and businesses on how to use online public administrative services in public service delivery projects. As a result, the experience of citizens and businesses in accessing and using information technology is limited [59].

\subsection{City Vision and Transformation-Opportunities}

\subsubsection{Institutional Interactions}

In the process of development, the city government pays special attention to building typical IT infrastructure to make the most of the fields to share data and information among people, businesses, 
and government [56]. City government facilitate permission specific benefits among stakeholders including integrate public services, conveniently access to real-time information and interact with the government in life activities [57]. It has been recognized that governance is one of the critical factors for smart city development [60]. It has the mission of ensuring the voluntary participation and service cooperation between various functional sectors and different stakeholders such as politics, the business community, academics, and nonprofit organizations to manage resources more effectively and serve citizens better [31,61].

\subsubsection{Citizen-Centric, Innovation and Entrepreneurship}

Governance is responsible for ensuring service participation and cooperation between various functional sectors and different stakeholders to manage resources more effectively [61,62]. Governance innovation can be improving the business environment through effective administrative reforms, reducing paper procedures, strengthening inspection registrations, granting electronic monitoring permits, interdisciplinary coordination, and meeting the requirements of the business [60]. Citizens, businesses, and the startup community can use open data to work together to build smart solutions that help solve common citywide problems [62]. In 2015, the Lee Kuan Yew School of Public Policy cooperated with Microsoft Corporation and Vietnam Computer Association to conduct a survey of 10 cities, including Dalat city [59]. Survey results show that Dalat city has been significantly changing in many aspects, including city management and development, especially ICT infrastructure upgrading and private economic development. Citizens and visitors have been provided with high-quality services on tourism, transport, health, education, the environment, which is guaranteed to improve the quality of life in Dalat [59].

\subsection{City Vision and Transformation-Threats}

\subsubsection{Economic Uncertainty}

The context of developing smart cities is not only in Dalat city, but most cities in Vietnam are under pressure by the heterogeneous economic policy in national and even international regulations, lacking data reporting as well as the limitations of forecasts of return on investment and public finance [63]. The needs of development capital are huge, but the government budget can only supply a small part, while private enterprises are hesitant because of the high risk of investing themselves in smart city projects [63]. All investments are subject to risks, smart city development such as smart infrastructure, new energy, energy-saving programs, and other smart investment areas always with a high level of risk to attract investment $[60,63]$.

\subsubsection{Lack of Universal Standardized and Interoperability Issues}

The city does not have a legal basis yet for building smart cities due to decisions and execution processes not been institutionalized yet, lacking selection of evaluation criteria, exceptionally consistent with the characteristics of the localities and country [56]. The Vietnamese government has not yet issued a mechanism, policy, or service cost; the initial services deployed in this form temporarily agreed between the government and private providers [50]. Some of the foundational data for developing smart cities such as data on digital maps, residential databases, land databases are just being implemented at a national level and progress may extend to after $2020[32,59]$.

\subsection{Suitable Strategies Framework for the Development of a Smart City in Dalat}

Smart city development is seen by a portion of literature as the application of intelligence to city management [64]. For a long time, cities' initiatives dominated by top-down approaches [65]. It can quickly be inferred that sharing and integrating information and knowledge is one of the most critical objectives. To achieve these goals, managerial interoperability across the city's smart services, applications, and organizations are vitally needed [66]. Early strategic planning for a range of services, 
with a focus on governance to allow integration among city departments to establish the platform to provide better services, build a common platform to creating synergy on technology infrastructure and capacity building in the city government [67].

In the smart city ecosystem, services should be facilitated based on nature and the needs of citizens [68]. In order to develop smart city services, the local government must plan cooperation between different division levels, effectively distribute funds, and formulate appropriate rules and regulations for different sectors of the city [69]. In general, the city needs to provide an overall development model, aiming to provide Dalat with a way and direction to be able to develop a smart city model to maximize consensus and reduce costs. Determining the best place to start the journey also helps city management adapt how to build and develop according to the model of the smart city in each period. Attracting public support and motivation in the journey; developing milestones; setting up metrics to evaluate performance and enabling scaling of success achieved throughout the process. Therefore, in this study, we propose an adaptive directions model for the city (Figure 4).

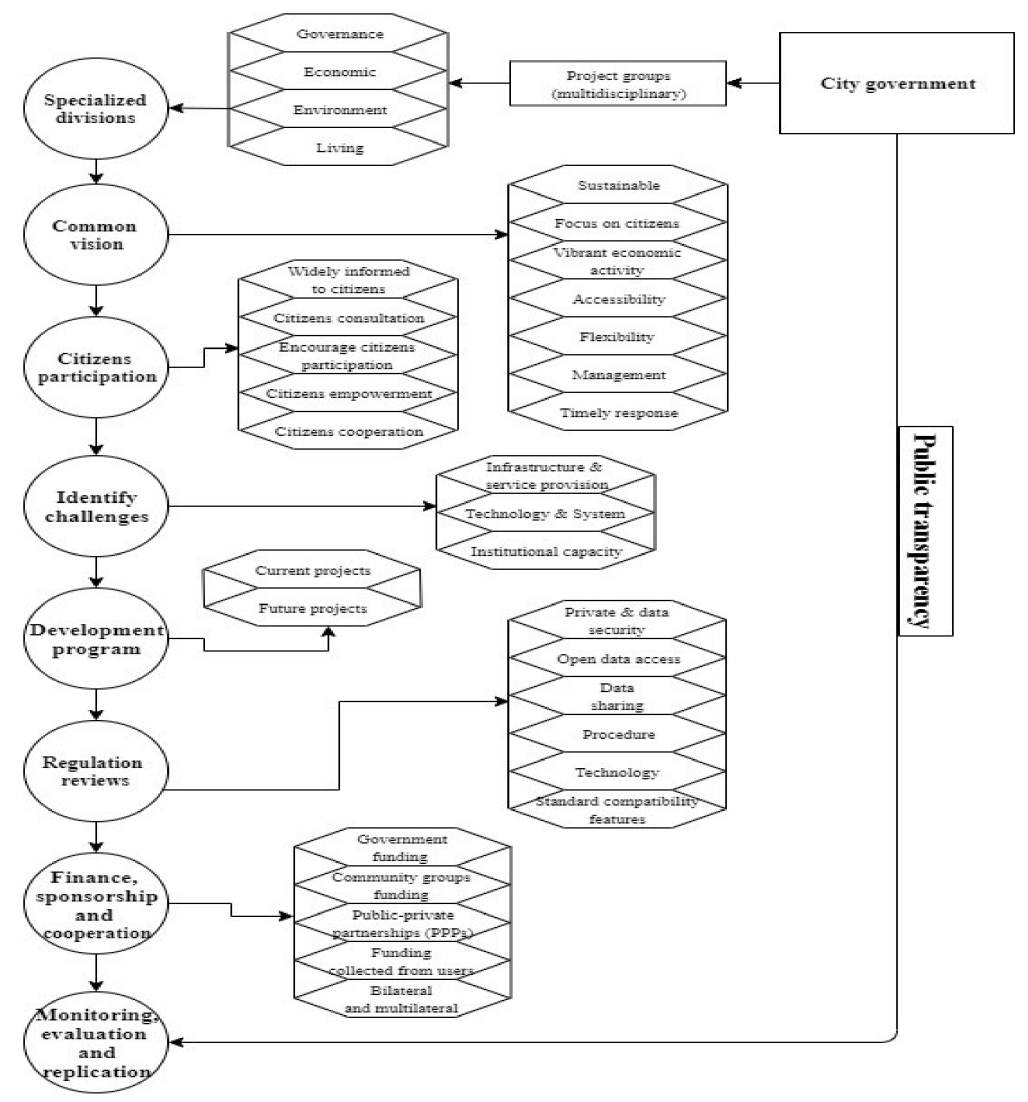

Figure 4. Strategic framework for smart city development.

\subsubsection{Specialized Divisions}

Designing and steering a shared vision of the city requires strong political leadership and a full understanding of the community (residents, businesses, organizations) requirements to inspire the vision and address local challenges [70]. Every smart city project needs visionary leaders and teams of competent projects to carry out the transition of the city to also be able to arrange human resources and connect between partners to realize the vision of the city. The management team and the project team must be able to build and protect the city's future vision by connecting the efforts of the authorities. The leadership may assume the role of providing overall strategic direction. However, the city also needs to appoint the team leader of this project team as this group will assume the primary responsibility for the development stages of the city following the smart city model. Team leaders can be those who know the roles of different authorities and departments in the city as well as the 
interconnected interactions between the parties. This team must consist of representatives from each field, have sufficient management knowledge and skills to make strategic and operational decisions, and are needed to implement city-level projects.

\subsubsection{Common Vision}

"Knowing oneself" is an important starting point to establish a vision for the future. Each city has its own economic and social characteristics, which are reflected in its physical facilities, culture, and heritage. Building a vision of the future must mainly be built on the structure of the city to match and resonate with the city's strengths, creating strong support and foundations for the city in the transition [61]. Once the project team is assembled and established, the city then needs to develop a long-term vision to set goals for this transition. Most cities have a long-term vision of seeing citizens as focal points and focus on social and economic sustainability [9]. The project team needs to develop a strategic vision based on taking into account the broader vision from the city such as a socio-economic development plan, master plan, regional and provincial plans and aspirations of the city.

\subsubsection{Citizens Participation}

A smart city is continually shaping and changing its strategy, combined with the views of its citizens, to bring maximum benefits to all. Most cities have set goals to develop smart cities to improve comfort and improve the quality of life of people. The people are the ones who use directly or indirectly the services of the smart city. Cities often do not achieve their smart goals if citizens, as the end-users, do not contribute their opinions to the design of smart cities. Failure to collect people's ideas early in the visioning process often leads to delayed consensus and will make it difficult to change behavior at a later stage [71]. One of the critical characteristics of a smart city is to encourage and engage people in the life of the city, including being involved in decision making and learning [72]. More and more cities are encouraging their citizens to participate in various stages of the transition to smart cities. Citizens' participation in the decision-making process has been tested in many cities when groups or the entire population is invited by state agencies to respond to decisions and views proposals on policies and new projects $[61,67,72]$. Linking people's participation also helps to bring out various solutions, which are the priorities that people identify, and many cities also organize events and contests so that people can build and together, create ideas for projects and technology solutions.

It should be noted that engaging people in the process of city-building is not about enabling them to approach city management but co-creating collective solutions and getting consent to a more generous agreement [73]. With these factors, the participation of citizens will bring significant benefits to the smart city model transformation process by expanding and getting closer to people through the city. Using technology/communication, through this plan, people will be closer to each other, which will create motivation to change citizens' behavior.

\subsubsection{Identify Challenges}

Cities face many challenges in many different areas such as urban planning, transformation, culture and entertainment, environment, organization, knowledge and skills, urban economy, and infrastructure (water, electricity, waste management, housing, and sanitation) e-government services and social infrastructure (health, security and other needs of people). The success of any smart city depends on how well it understands current and future challenges, including the current capacity of its departments to address the challenges [67]. In other words, understanding the city's limitations and the complexity of projects is crucial in the transition to the smart city model. Cities need to take a few steps to convert to smart cities, one of the essential steps in building a foundation is to identify the most urgent challenges that the city and its people need to address while maintaining a multidisciplinary and collaborative vision. While identifying physical infrastructure is a complex process, checking the city's technological infrastructure and the departments that provide these services is even more complex [35]. Parameters such as data sensors, connectivity, system, and device interoperability need to carefully 
research. Once the physical infrastructure challenge and technology fulcrum that supports these infrastructures are completed, the city needs to focus more on the institutional capacity to implement successful projects of smart cities [74]. Therefore, a review should focus on three key factors: service delivery level and physical infrastructure issues, technological and system challenges, and diagnosis of organizational/institutional capacity for the future.

\subsubsection{Development Programs}

Once the vision and priorities have been developed, as well as after researching to assess specific challenges, the city needs to develop programs with project portfolio identification to seek results. It is necessary to focus on the results and objectives of the project, rather than specific technical solutions to addressing challenges [75]. Multidisciplinary and multi-domain programs should be developed so that traditional platforms and new projects can bring together optimal results. The city must determine the right scope and scale of the projects because, for some projects, it will take time and money to achieve success on a city-wide scale. The city must come up with specific multidisciplinary solutions/programs/topics by clearly defining the costs involved, the sources of funding that can be called for, the conventional benefits, the timing of implementation, along with the role of different authorities. The city also needs to remain focused on existing projects, and all new programs or projects are not necessarily preliminary projects. Ideas for improving and extending positive implementation steps may also be a necessary strategy to apply [76]. At this stage, another critical task is to determine a more suitable measure for project management. The right metrics depend significantly on a clear understanding of what the city wants to achieve. Measurements should be developed in conjunction with the corresponding methods to know if the project will achieve its final goal.

\subsubsection{Regulation Reviews}

In the transformation of the smart city model, the city will take advantage of solutions based on innovative business models that appropriate legal frameworks. New policies, regulations, and methods are needed for the successful building of a smart city model [77]. Applying overlaps between existing policies and new regulations on implementing smart city models will not be sufficient. Depending on the issues that the smart city program needs to solve, the city will have to refine the rules to address concerns about data privacy, data security, encouraging open data access and data sharing. All of this must be done in a transparent and responsible manner to be able to attract and build trust for users because data will accessed from all sources, a comprehensive and smart ecosystem needs standard application and high interoperability [78]. Because data sharing and access are critical to the success of smart cities, clear rules and legal formulation may be required. In order to be consistent in developing smart cities, developers in Dalat city need to follow some standards such as processes, technologies, frameworks and standard compatibility features. So, to achieve a uniform and objective scale of one smart city, the first important step is to study the standards that will be applied. The city should carefully review the list of standards as these indicators will give suggestions for the level of compliance that a city will need to maintain in order to achieve the criteria of a smart city. Standards for smart cities can be used to monitor engineering activity, ensure safety, interoperability, cost-cutting, effective strategic planning, and management of resources [26,78]. Besides, standards can be used to evaluate best practices. Standards provide a common language and knowledge base, promote uniform solutions, and promote public-private partnerships [76]. Finally, standards are tools and guidelines for the city to deploy solutions with great potential in the market and receive wide approval from the authorities.

\subsubsection{Finance, Sponsorship and Cooperation}

Admittedly, it is financially difficulty to deploy smart city technology development, especially when budgets are limited. An important step in an attempt to build a smart city model is evaluating all potential funding options soon and identifying the sources of financing, or which combination can 
provide an excellent financial solution best to bring a project from idea to reality. Donor coordination can extend from the public and public agencies to innovative and private financing options. It is important to consider a well-structured business case, which identifies costs and quantifies benefits over the life of the project in the city procurement plan [79]. The procurement strategy of the departments is also essential to be an integrated strategy to gain economic benefits, eliminate unnecessary costs, and allow interaction. Cities may consider possible sources of financing. Another vital activity while considering financial and financial resources is the search for partners (private, academia, institutions, NGOs, technology solution providers), these partnerships are important both technically and from a fundraising perspective. Choosing the right financial source with the ability to realize with the right partner is an important stage in determining the success of the city-building efforts of the smart city model [54].

To build a smart city, it needs to focus on the short-term success of building its brand, attracting human resources as well as solutions and investments. Projects that can be completed and have a fast return on investment need to be prioritized. Some initial achievements are essential for any city when embarking on a quick city transition. Initial success will build the confidence and motivation necessary to accelerate the transition. Initial success can build on the principle of selecting projects that are profitable fast and large compared to the capital and time required to invest [80]. With the support of a number of smart city researchers and advisors, several areas can be selected for initial success.

\subsubsection{Monitoring, Evaluation and Replication}

When the first successful projects are put into practice, an important parallel activity will be to establish metrics to measure progress towards project results and set goals. Projects should be regularly monitored to minimize costs incurred and schedule delays and ensure the desired quality. Benefits gained from implemented projects must be disseminated at all levels, and the Key Performance Indicator (criteria) of the project must not be achieved, and necessary modifications must be made. Such surveys also allow the city government to know and find out what technological solutions are worth investing in future projects. Tracking, evaluating, and providing feedback are vital for the smart city learning process [81]. The results seen through each project, even small projects, together with transparency and public participation, will create a significant motivation for other projects in the future. Once the city government implements and evaluates, which projects lead to success and builds a positive awareness, the ability to replicate and expand those projects can be studied for implementation at a more suitable scale.

\section{Conclusions}

Deploying smart city construction is an indispensable trend of any city all over the world in the context of the fourth industrial revolution taking place globally. The deployment of smart city construction is a permanent solution for Dalat city to solve the problems that it currently encounters, improve the quality of life, and promote economic development. However, the study shows that making the smart city in Dalat is not an easy task. The deployment of a smart city in Dalat city is a complex, long-term process requiring the participation of many social sectors, many specialized forces, and the consensus and determination of both city authorities and citizens. Firstly, the city needs a complete change of policy and ICT infrastructure to solve any situation through a long term vision. Secondly, building up human resources, ready to meet the demands of smart city development is required. Thirdly, the city must frequently provide wide communication broadcasting and guides for citizens and businesses to apply online public administrative services, to ensure the participation of citizens based on transparency.

Limitations of this study should be addressed. Firstly, the drawback of SWOT analysis is that there is no theoretical support needed to confirm the typical structure yet. This may be attributable to the fact that SWOT analysis is one of fast scanning at a time due to the environment and new strategies continuously changing. Continuing to analyze SWOT over time can improve positioning and strategic 
leverage, but it is necessary to combine SWOT with other powerful analytical tools to get detailed and relevant insights. Secondly, critical information and data reflect the accuracy of the results at the time of the study. However, due to the fact that information management of the government is relatively difficult, some data, as well as specific limitations of cities, need to be further exploited by working correctly with local authorities. This study contributes to Dalat city, providing a SWOT analysis; it will form the basis of a broader discussion on the introduction of solutions and implementation of detailed smart city construction. The study serves as a consultation for managers and is the basis for analyzing the effectiveness of actions related to proposed strategies. The evaluation results received may serve as a starting point for further evaluation analysis. The study contributes as a reference for other cities in Vietnam interested in analyzing the foundations of smart city building strategies.

Author Contributions: Conceptualization, K.H.V.B.; Formal analysis, K.H.V.B.; Funding acquisition, K.H.V.B.; Investigation, K.H.V.B.; Methodology, K.H.V.B.; Project administration, K.H.V.B.; Resources, K.H.V.B.; Supervision, S.-K.K.; Writing-original draft, K.H.V.B.; Writing-review \& editing, K.H.V.B. All authors have read and agreed to the published version of the manuscript.

Funding: This research received no external funding.

Conflicts of Interest: The authors declare no conflict of interest.

\section{References}

1. UN DESA. World Urbanization Prospects: The 2018 Revision; United Nations: Department of Economic and Social Affairs/Population Division: New York, NY, USA, 2018.

2. Cohen, B. Urbanization in developing countries: Current trends, future projections, and key challenges for sustainability. J. Technol. Soc. 2006, 28, 63-80. [CrossRef]

3. Kearns, A.; Paddison, R. New Challenges for Urban Governance. Urban Stud. 2000, 37, 845-850. [CrossRef]

4. Mutemeri, N.; Callaghan, C.; Hermanus, M. Good Practice Note Public Infrastructure and Mining; University of the Witwatersrand: Johannesburg, South Africa, 2010.

5. Tallman, S.; Fladmoe-Lindquist, K. Internationalization, Globalization, and Capability-Based Strategy. Calif. Manag. Rev. 2002, 45, 116-135. [CrossRef]

6. Choongik, C.; Chun-il, K. The 4th Industrial Revolution, Smart Cities, and Sustainable Urban Regeneration: A Perspective Study. J. Environ. Policy Admin. 2017, 25, 61-91.

7. PWC. Global Industry 4.0 Survey, Industry 4.0: Building the Digital Enterprise. Available online: https://www.pwc. com/gx/en/industries/industries-4.0/landing-page/industry-4.0-building-your-digital-enterprise-april-2016.pdf (accessed on 3 September 2019).

8. IHS Technology. Smart Cities to Rise Fourfold in Number from 2013 to 2025. Available online: https://news. ihsmarkit.com/press-release/design-supply-chain-media/smart-cities-rise-fourfold-number-2013--2025 (accessed on 6 September 2019).

9. Mulligan, C.E.A.; Olsson, M. Architectural implications of smart city business models: An evolutionary perspective. IEEE Commun. Mag. 2013, 51, 80-85. [CrossRef]

10. Dameri, R.P.; Rosenthal-Sabroux, C. Smart City. In Smart City and Value Creation; Dameri, R.P., Rosenthal-Sabroux, C., Eds.; Springer: Cham, Switzerland, 2014; pp. 1-12.

11. World Bank, MPI. Vietnam 2035: Toward Prosperity, Creativity, Equity, and Democracy; The World Bank Group: Washington, DC, USA, 2016.

12. Hieu, N.N. Urban boundary and growth management in the peri-urban area. Vietnam. Archit. 2015, 12, $24-31$.

13. World Bank. Vietnam Urbanization Review_Technical Assistance Report Vietnam; The World Bank Group: Washington, DC, USA, 2011.

14. UN-Habitat. Vietnam Housing Sector Profile; UN-Habitat: Nairobi, Kenya, 2014.

15. Ha, C.T.T. Environmental Pollution in Vietnam: Challenges in Management and Protection. J. Viet. Env. 2018, 9, 1-3.

16. Vietnam Government Portal. Decision No. 950/QD-TTG Dated 01/08/2018. Available online: http://vanban.chinhphu. vn/portal/page/portal/chinhphu/hethongvanban?class_id=2\&_page=1\&mode=detail\&document_id=194337 (accessed on 10 November 2019). 
17. MIC. Vietnam ICT Index Anual Report 2017; Vietnam government, Ministry of Information and Communications: Ha Noi, Vietnam, 2017.

18. Araya, D. Smart Cities and the Network Society: Toward Commons-Driven Governance. In Smart Cities as Democratic Ecologies; Araya, D., Ed.; Palgrave Macmillan: Houndmills, UK; ASC: Amsterdam, The Netherlands, 2015; pp. 11-22.

19. Kumar, T.M. E-democracy for Smart Cities. In Advances in 21st Century Human Settlements; Kumar, T.M., Ed.; Springer International Publishing: Singapore, 2017; pp. 1-47.

20. Yang, C.; Huang, Q.; Li, Z.; Liu, K.; Hu, F. Big data and cloud computing: Innovation opportunities and challenges. Int. J. Digit. Earth 2017, 10, 13-53. [CrossRef]

21. Komninos, N. Intelligent cities: Towards interactive and global innovation environments. Int. J. Innov. Reg. Dev. 2009, 1, 337-355. [CrossRef]

22. Kramers, A.; Höjer, M.; Lövehagen, N.; Wangel, J. Smart sustainable cities-exploring ICT solutions for reduced energy use in cities. Environ. Model Softw. 2014, 56, 52-62. [CrossRef]

23. Neirotti, P.; De Marco, A.; Cagliano, A.C.; Mangano, G.; Scorrano, F. Current trends in smart city initiatives: Some stylised facts. Cities 2014, 38, 25-36. [CrossRef]

24. Niaros, V.; Kostakis, V.; Drechsler, W. Making in the smart city: The emergence of makerspaces. Telemat. Inform. 2017, 34, 1143-1152. [CrossRef]

25. Wolfram, M. Deconstructing Smart Cities: An Intertextual Reading of Concepts and Practices for Integrated Urban and ICT Development. In Proceedings of the Real Corp 2012: Re-Mixing the City-Towards Sustainability and Resilience, Aachen, Germany, 14-16 May 2012.

26. Giffinger, R.; Fertner, C.; Kramar, H.; Kalasek, R.; Pichler-Milanovic, N.; Meijers, E. Smart Cities: Ranking of European Medium-Sized Cities. Available online: http://www.smart-cities.eu/download/smart_cities_final_ report.pdf (accessed on 10 November 2019).

27. Pelley, J. Building smart-growth communities. Environ. Sci. Technol. 1999, 33, 28-32. [CrossRef] [PubMed]

28. Meijer, A.; Bolívar, M.P.R. Governing the smart city: A review of the literature on smart urban governance. Int. Rev. Adm. Sci. 2016, 82, 392-408. [CrossRef]

29. Zaheer, A.; Peter, N. Redefining the Smart City: Culture, Metabolism and Governance. Smart Cities 2018, $1,4-25$

30. ITU. What is a smart Sustainable City? Available online: http://itunews.itu.int/en/5215-what-is-a-smartsustainable-city.note.aspx (accessed on 12 September 2019).

31. Zygiaris, S. Smart city reference model: Assisting planners to conceptualize the building of smart city innovation ecosystems. J. Knowl. Econ. 2012, 4, 217-231. [CrossRef]

32. Vietnam Ministry of Construction. Smart City Vision in Vietnam. Available online: http://www.moc.gov.vn/ vi/thong-tin-tu-lieu/-/tin-chi-tiet/ek4I/86/447727/tam-nhin-do-thithong-minh-tai-viet-nam.html (accessed on 16 September 2019).

33. PRB. An Overview of Population and Development in Vietnam. Available online: https://www.prb.org/ anoverviewofpopulationanddevelopmentinvietnam/ (accessed on 16 September 2019).

34. Fraser, C. E-government: The Canadian experience. Dalhousie J. Interdiscip. Manage. 2009, 5, 1-14.

35. Mattoni, B.; Gugliermetti, F.; Bisegna, F. A multilevel method to assess and design the renovation and integration of smart cities. Sustain. Cities Soc. 2015, 15, 105-119. [CrossRef]

36. Dennis, L. From e-government to we-government: Defining a typology for citizen coproduction in the age of social media. Gov. Inform. Q. 2012, 29, 446-454.

37. Maria, L.M.L.; Joan, C.L.; Joaquim, M.F. Lessons in urban monitoring taken from sustainable and livable cities to better address the Smart Cities initiative. Technol. Forecast. Soc. 2015, 90, 611-622.

38. Kehua, S.; Jie, L.; Hongbo, F. Smart city and the applications. In Proceedings of the 2011 International Conference on Electronics, Ningbo, China, 9-11 September 2011.

39. Eleonora, R.S.; Raffaella, R.S.; Valentina, V.; Ina, M.; Enrico, A. Smart Cities: Case Studies. In Smart Cities Atlas; Eleonora, R.S., Raffaella, R.S., Valentina, V., Eds.; Springer: Cham, Switzerland, 2017; pp. 47-140.

40. Coman, A.; Ronen, B. Focused SWOT: Diagnosing critical strengths and weaknesses. In. J. Prod. Res. 2009, 47, 5677-5689. [CrossRef]

41. Houben, G.; Lenie, K.; Vanhoof, K. A knowledge-based SWOT-analysis system as an instrument for strategic planning in small and medium sized enterprises. Decis. Support Syst. 1999, 26, 125-135. [CrossRef]

42. Warren, K. Strategic Management Dynamics; Warren, K., Ed.; John Wiley \& Sons: New York, NY, USA, 2008. 
43. Marques, J.F. How Politically Correct Is Political Correctness? A SWOT Analysis of This Phenomenon. Bus. Soc. 2009, 48, 257-266. [CrossRef]

44. Evans, C.; Wright, A. How to conduct a SWOT analysis. Br. J. Manag. 2009, 24, 10-34.

45. Helms, M.M. Exploring SWOT analysis-where are we now?: A review of academic research from the last decade. J. Strat. Manag. 2010, 3, 215-251. [CrossRef]

46. Gunn, R.; Williams, W. Strategic tools: An empirical investigation into strategy in practice in the UK. Strateg. Chang. 2007, 16, 201-221. [CrossRef]

47. Grant, R.M. Why strategy teaching should be theory based. J. Manag. Inq. 2008, 17, 276-291. [CrossRef]

48. Gibis, B.J.; Corabian, P.; Meiesaar, K.; Koppel, A.; Jacobs, P. Application of strengths, weaknesses, opportunities and threats analysis in the development of a health technology assessment program. Health Policy 2001, 58, 27-35. [CrossRef]

49. Somers, M.J.; Passerini, K.; Parhankangas, A.; Casal, J. Using mind maps to study how business school students and faculty organize and apply general business knowledge. Int. J. Manag. Educ. 2014, 12, 1-13. [CrossRef]

50. Kern, C.S.; Bush, K.L.; McCleish, J.M. Mind-mapped care plans: Integrating an innovative educational tool as an alternative to traditional care plans. J. Nurs. Educ. 2006, 45, 112-119. [CrossRef]

51. Lamdong Government. Resolution No. 03-NQ/TW Dated 13/09/2016. Available online: http://www.lamdong. gov.vn/vi-VN/a/vankiendang/Lists/VB\%20QPPL/Attachments/99/nqs03.pdf (accessed on 25 August 2019).

52. Khoa, H.V.B.; Sung-Kyun, K. Developing Smart City: Based on the Assessment of Smart Projects in Medium-Size Cities, Vietnam. Am. Sci. Res. J. Eng. Technol. 2019, 56, 38-49.

53. Glasmeier, A.; Christopherson, S. Thinking about Smart Cities. Camb. J. Regions. Econ. Soc. 2015, 8, 3-12. [CrossRef]

54. Lazaroiu, G.C.; Roscia, M. Definition methodology for the smart cities model. Energy 2012, 47, $326-332$. [CrossRef]

55. Schuurman, D.; Baccarne, B.; De Marez, L. Mechant, Smart ideas for smart cities: Investigating crowdsourcing for generating and selecting ideas for ICT innovation in a city context. J. Theor. Appl. Electron. Commer. Res. 2012, 7, 49-62. [CrossRef]

56. Lamdong Government. Implementation of the Project Building Dalat City Become a Smart City Period 2018-2025; Department of Information and Communication: Dalat, Vietnam, 2019.

57. DalatCity People's Committee. Implementation of Dalat-Online Application; Dalat Government: Dalat, Vietnam, 2019.

58. Nam, T.; Pardo, T.A. The changing face of a city government: A case study of Philly311. Gov. Inf. Q. 2014, 31, S1-S9. [CrossRef]

59. Lamdong Government. Project of Building Dalat to Become a Smart City in the Period of 2017-2020; Office of Lamdong Provincial People's Committee: Dalat, Vietnam, 2017.

60. Irfan, A.H.; Anwar, A.S.; Muhammad, A.U.; Bhawani, S.C.; Tahir, R. Multi-criteria assessment of smart city transformation based on SWOT analysis. In Proceedings of the 2015 th National Symposium on Information Technology: Towards New Smart World (NSITNSW), Riyadh, Saudi Arabia, 17-19 February 2015.

61. King, S.; Cotterill, S. Transformational government? The role of information technology in delivering citizen-centric local public services. Local Gov. Stud. 2007, 33, 333-354. [CrossRef]

62. Lee, J.; Lee, H. Developing and validating a citizen-centric typology for smart city services. Gov. Inf. Q. 2014, 31, 93-105. [CrossRef]

63. Hall, P. Creative cities and economic development. Urban Stud. 2000, 37, 633-649. [CrossRef]

64. Boulton, A.; Brunn, S.D.; Devriendt, L. Cyber Infrastructures and "Smart” World Cities: Physical, Human, and Soft Infrastructures. In International Handbook of Globalization and World Cities; Taylor, P., Derudder, B., Hoyler, M., Witlox, F., Eds.; Edward Elgar: Cheltenham, UK, 2011.

65. Schaffers, H.; Komninos, N.; Pallot, M. Smart Cities as Innovation Ecosystems Sustained by the Future Internet. Available online: https://www.urenio.org/wp-content/uploads/2012/04/2012-FIREBALL-WhitePaper-Final.pdf (accessed on 10 November 2019).

66. Nam, T.; Pardo, T. Conceptualizing smart city with dimensions of technology, people, and institutions. In Proceedings of the 12th Annual International Digital Government on Research Conference on Digital Government Innovation in Challenging Times, College Park, MD, USA, 12-15 June 2011. 
67. Lee, J.H.; Hancock, M.G.; Hu, M.C. Towards an effective framework for building smart cities: Lessons from Seoul and San Francisco. Technol. Forecast. Soc. Chang. 2014, 89, 80-99. [CrossRef]

68. Lee, J.H.; Phaal, R.; Lee, S.H. An integrated service-device-technology roadmap for smart city development. Technol. Forecast. Soc. Chang. 2013, 80, 286-306. [CrossRef]

69. Landsbergen, D.J.; Wolken, G., Jr. Realizing the promise: Government information systems and the fourth generation of information technology. Public. Admin. Rev. 2001, 61, 206-220. [CrossRef]

70. Soumaya, B.L. How to strategize smart cities: Revealing the SMART model. J. Bus. Res. 2015, 68, 1414-1419.

71. Li, C.S.; Darema, F.; Chang, V. Distributed behavior model orchestration in cognitive internet of things solution. Enterp. Inf. Syst. 2017, 12, 414-434. [CrossRef]

72. Weisi, F.; Ping, P. A discussion on smart city management based on meta-synthesis method. Manag. Sci. 2014, 8, 68-72.

73. Allwinkle, S.; Cruickshank, P. Creating smarter cities: An overview. J. Urban Technol. 2011, 18, 1-16. [CrossRef]

74. Caprotti, F.; Cowley, R. Interrogating Urban Experiments. Urban Geogr. 2017, 38, 1441-1450. [CrossRef]

75. Dupont, L.; Morel, L.; Guidat, C. Innovative public-private partnership to support Smart City: The case of "Chaire REVES". J. Strateg. Manag. 2015, 8, 245-265. [CrossRef]

76. Novotný, R.; Kuchta, R.; Kadlec, J. Smart city concept, applications and services. J. Telecommun. Syst. Manag. 2014, 3, 117.

77. Dahiya, B. Cities in Asia 2012: Demographics, economics, poverty, environment and governance. Cites 2012, 29, 44-61. [CrossRef]

78. Bulu, M. Upgrading a city via technology. Technol. Forecast. Soc. Chang. 2014, 89, 63-67. [CrossRef]

79. Abastante, F.; Lami, I.M.; Lombardi, P. An Integrated Participative Spatial Decision Support System for Smart Energy Urban Scenarios: A Financial and Economic Approach. Buildings 2017, 7, 103. [CrossRef]

80. Kinawy, S.; El-Diraby, T.; Konomi, H. Customizing information delivery to project stakeholders in the smart city. Sustain. Cities Soc. 2018, 38, 286-300. [CrossRef]

81. Orłowski, C.; Ziółkowski, A.; Orłowski, A.; Kapłański., P.; Sitek, T.; Pokrzywnicki, W. Designing Aggregate KPIs as a Method of Implementing Decision-Making Processes in the Management of Smart Cities. In Transactions on Computational Collective Intelligence XXV_Lecture Notes in Computer Science; Nguyen, N., Kowalczyk, R., Orłowski, C., Ziółkowski, A., Eds.; Springer: Berlin/Heidelberg, 2016; Volume 9990. 